\title{
O AGRONEGÓCIO DA SOJA E AS VIOLAÇÕES DO DIREITO À CIDADANIA E AO DESENVOLVIMENTO RURAL: UM ESTUDO DE CASO DAS COMUNIDADES LOCAIS DE SANTARÉM-PA, BRASIL
}

Jonismar Alves Barbosa

0 autor é Advogado, mestre em Direitos Humanos pelo PPGD-UFPA (Brasil) e doutorando em Direito Ambiental pela Universidade de Alicante, Espanha, bolsista da CAPES para Doutorado Pleno no Exterior-Processo BEX 0689/14-9. 0 autor é Doutor Honoris Causa pela Universidade do Vale do Itajaí (UNIVALI). Contato: jonismar@hotmail.com

Gabriel Real Ferrer

0 autor é Doutor Honoris Causa pela Universidade do Vale do Itajaí (UNIVALI). Possui Doutorado em Direito pela Universidade de Alicante (1992), é Professor Titular de Direito Ambiental e Administrativo e Subdiretor do Instituto Universitário da Água e do Meio Ambiente na mesma Universidade e é Consultor do Programa das Nações Unidas (ONU) para o Meio Ambiente PNUMA.

\section{Resumo}

O presente trabalho discorre sobre a dinâmica criada pela cadeia produtiva de soja em Santarém, Pará, Brasil e seus reflexos na vida dos povos tradicionais, que habitam essa parte da Amazônia. Demonstra que a soja é responsável pela violação do direito fundamental de acesso à terra das comunidades locais em Santarém. Destaca que o agronegócio é responsável pela alteração dos modos de criar, fazer e viver dos povos tradicionais, demonstrando, por meio de pesquisa bibliográfica e em loco uma realidade violadora de direitos de cidadania que impede, sobretudo, o desenvolvimento rural sustentável da região.

\section{Palavras-chave}

Agronegócio; Soja; Amazônia; Desarrollo Rural; Cidadania; Comunidades Tradicionais.

\section{Resumen}

En este trabajo se analiza el impulso creado por la cadena productiva de la soja en Santarém, Pará, Brasil y sus impactos en la vida de los pueblos tradicionales que habitan 
en esta parte de la Amazonía. Se busca demonstrar que la soja es responsable por la violación del derecho fundamental de acceso a la tierra de las comunidades locales en Santarém. Enseña que el agronegocio es responsable por cambiar las formas de crear, hacer y vivir de los pueblos tradicionales, enseñando por medio de la literatura sobre el asunto y por medio de un trabajo de campo una realidad violadora de derechos de ciudadanía qué impide, en especial, el desarrollo rural sostenible de la región.

\section{Palabras clave}

Agronegocio; Soja; Amazonía; Desarrollo Rural; Ciudadanía; Comunidades Tradicionales.

\section{Introdução}

A história agrária do Brasil sempre esteve marcada por processos de ocupação e apropriação que atendiam mais interesses políticos ou de classes dominantes do que a projetos ou estratégias de desenvolvimento local, regional ou nacional, e esse modo de apropriação indiscriminada da terra fomentou no país uma estrutura fundiária concentrada e desigual distribuição de riqueza agrária, ocasionando, sobretudo, problemas socioambientais aos pequenos agricultores e comunidades tradicionais ${ }^{1}$.

E esse modelo de apoderamento da terra no decorrer do tempo, assim como ocorreu em outras partes do mundo, fez com que fossem buscados métodos mais eficazes de exploração dos recursos naturais, de modo a aumentar a produção agrícola e gerar mais riquezas a seus proprietários, todavia, também gerou inúmeros problemas às populaçóes que estavam diretamente envolvidas com a exploração agrícola, sobretudo, as que gozavam de menos partes territoriais ou faziam parte de minorias e já ocupavam a região antes da chegada dos grandes produtores.

O governo brasileiro por décadas instituiu vários programas de valorização do homem do campo, com isso, pretendia fazer uma modernização e afirmaçáo nacional vinculada ao conceito de civilização democrática, no qual o cerne era um cidadão campesino vinculado a uma forma social, considerada desenvolvida, que se sobrepunha a qualquer tipo de identidade sociocultural.

E por muito tempo a própria formação histórica do Brasil foi renegada em termos de valorização e proteção socioambiental, já que as formas sociais de produção agropecuária eram construídas sob a figura do latifundiário, cuja protagonista desse cenário era uma classe agroprodutora burguesa, enquanto que as demais, o pequeno granjeiro, os pequenos

1 Para melhor entendimento sobre o conceito de povos tradicionais e socioambientalismo, por favor ver a obra de SANTILLI, Juliana, Socioambientalismo e novos direitos. São Paulo: Petrópolis, IEB, 2005. 
agricultores tradicionais, a entidade familiar cabocla de subsistência, quilombola e indígena eram olvidadas por completo.

No entanto, a crescente valorização das atividades rurais resultante das lutas sociais, especialmente aquelas voltadas para a remuneração do trabalho (preços agrícolas), reconhecimento de minorias, de respeito à sociobiodiversidade, às comunidades étnicas, às preocupaçóes com a defesa do meio ambiente e o socioambientalismo, fizeram com que houvesse uma ampliação do conceito de cidadania campesina, inserindo grupos que embora sempre tenha feito parte da cena rural viessem a ter mais ênfase dentro desse contexto, tais como as mulheres que estáo agora alterando o estatuto de dona de casa para trabalhadoras rurais.

A valorização de todos esses atores no campo fez com que a luta pela posse e manutenção do acesso à terra fosse ampliada, de modo a se pedir em todas as regióes do país cada vez mais uma reforma agrária e o reforço à proteção do modelo de agricultura familiar.

Segundo o IBGE (censo de 2006), a presença da agricultura familiar é forte no cenário rural brasileiro, constituindo cerca 4,1 milhốes (ou $3 / 4$ do total) de propriedades, ocupando somente 30\% das terras. Absorve 77\% (13,8 milhôes, segundo o Ministério do Desenvolvimento Agrário) da força de trabalho do setor, produzindo $37 \%$ da riqueza agropecuária e cerca de $60 \%$ dos alimentos consumidos pelos brasileiros, especialmente cereais, leite, carnes, frutas, verduras e café e é ela também que produz parte significativa da matéria prima para indústria e contribui com cerca de $30 \%$ das exportaçóes agropecuárias brasileiras.

Porém, em que pese tamanha importância, muitas vezes a agricultura familiar feita por comunidades de agricultores tradicionais, étnicas ou de migrantes é sempre afetada por algo que foge ao controle destas e, que na maioria das vezes, é incentivado, instalado e acobertado pelos governos locais, o agronegócio.

De norte a sul do Brasil não inúmeros os relatos de violaçôes de direitos dos pequenos agricultores por parte de donos de agronegócios.

Os problemas são desde apropriação indevida de terras, violência e morte no campo em virtude da luta pelo acesso a estas, perda de ecossistemas, da sociobiodiversidade local, bem como problemas de saúde desencadeados pela exploração do agrobussiness em larga escala.

Outro grave problema desencadeado pelo agronegócio no Brasil é a perda de identidade local pela invasão das novas culturas e modos de vida diversos daqueles mantidos pelas comunidades, há ainda a falta de acesso a bens e serviços comunitários, tais como a perda e/ou falta de contato entre membros da comunidade, a extinção dos vínculos e exercícios normais de cidadania, práticas culturais e religiosas, que tem posto em risco ou 
tem levado ao desaparecimento comunidades locais inteiras em algumas partes do território brasileiro, sobretudo na Amazônia.

Para melhor entendermos sobre o assunto, trazemos à baila estudo de caso feito no município de Santarém, no Pará, no ano de 2012, cujo alvo da pesquisa foram as consequências do agronegócio da soja para as comunidades locais ali existentes.

Pela análise dos dados coletados durante o trabalho de campo, se pôde perceber que as consequências da implantação da soja no oeste do estado paraense foram muito danosas, pois esta veio a desencadear uma série de eventos irreversíveis para a região: aumentou o desmatamento, a grilagem, o conflito pela posse e acesso à terra, dizimou modos de vida, afetou a agricultura familiar local, reduziu direitos básicos dos cidadãos campesinos, pois extinguiu acesso a bens e serviços de várias comunidades locais e contribuiu para a propagação de doenças, dentre vários outros fatores prejudiciais aos direitos fundamentais das comunidades ali residentes.

Todavia, neste trabalho vamos nos ater mais ao agronegócio da soja e sua relação direta com as violaçóes do direito à cidadania e ao desenvolvimento rural em Santarém, de modo a demonstrar claramente todas as interfaces dessa atividade produtora e suas consequências para as comunidades locais daquela região.

\section{Problematização}

O agronegócio da soja tem contribuído para a perda do território de comunidades tradicionais em Santarém, acirrando o conflito entre produtores e campesinos mediante o processo desordenado de ocupação das terras, além de interferir diretamente nos modos de fazer, criar e viver dessas populaçóes, bem como vem privando-as da chance de desarrolhar todas suas liberdades e potencialidades de desenvolvimento econômico e social.

Este tipo de atividade agroeconômica tem afetado direitos fundamentais de diversas comunidades locais em Santarém, sobretudo, os de cidadania, de identidade cultural, de liberdade e até mesmo o direito à vida. Diante disso, indaga-se, seria então o agronegócio um fator de impedimento ao desenvolvimento rural da região amazônica?

Segundo Fearnside, os plantios de soja têm substituído as pastagens em grande parte do município e vem causando discórdia entre os grandes produtores da oleaginosa e as entidades ligadas à proteção do meio ambiente, em virtude da grande extensão territorial que ocupam, além de causar sérios problemas aos povos tradicionais².

2 FEARNSIDE, Philip .M. O cultivo da soja como ameaça para o meio ambiente na Amazônia brasileira In: L.C. Forline, R.S.S. Murrieta and I.C.G. Vieira (eds.) Amazônia além dos 500 Anos. Museu Paraense Emílio Goeldi, Belém, Pará, Brasil, 2006, pp. 292-293. 
Em Santarém, a maioria dos depoimentos de agricultores e lideranças sindicais é marcada pela preocupação com a transferência de terras de produtores familiares e de povos tradicionais aos sojicultores, o que tem resultado no esvaziamento e desaparecimento de diversas vilas.

As comunidades afetadas sofrem não só com a perda da terra em si, com a perda dos modos de fazer, criar e viver, mas também, quando ficam nas propriedades, sofrem ainda com a perda de identidade cultural, com a falta de acesso a serviços básicos, como saúde, educação e transporte e se submetem a práticas insustentáveis e atentatórias aos seus direitos mais elementares, tais como o livre exercício da cidadania, de liberdade socioeconômica e ao direito à saúde como veremos mais adiante.

Com a chegada do agrobusiness e, consequentemente, com a perda de grande áreas territoriais, o acesso a serviços públicos como transporte, educação e saúde tornaram-se mais difíceis ou foram inviabilizados, tendo em vista o deslocamento das pessoas das comunidades para outros locais ou mesmo para o interior da floresta. Além disso, devido a essa dinâmica de dominação do território, se tem notícia de que a convivência comunitária deixou de existir em muitas localidades e as perdas sociais e culturais são irreversíveis ${ }^{3}$.

O cultivo de soja foi inserido no coração da regiáo amazônica paraense com intuito de desenvolvê-la, trazer renda e gerar empregos, entretanto, o que se tem visto, na maioria dos casos, é o contrário disso, haja vista que o plantio é feito por grandes produtores que abusam da mecanização e dos agrotóxicos nos campos, desrespeitando o modo de vida e as atividades agrícolas socioambientalmente corretas que antes eram desenvolvidas na região.

Ao sair das áreas de plantação alguns campesinos tradicionais que ficam em outras partes da floresta são obrigados a desmatar mais uma vez, já que sobrevivem da agricultura de subsistência, ou, quando não, são obrigados a viver nas cidades, em condiçóes sub-humanas, sem nenhum direito fundamental garantido, isso quando não migram para outros municípios ou estados.

A necessidade de plantio em grandes propriedades, o uso de maquinário de grande porte e de infraestrutura para armazenamento são fatores que forçaram parte dos pequenos produtores a migrar para outras regióes, vendendo suas terras para os mais capitalizados.

Outro fator preocupante é que além da presença de milhares de famílias tradicionais na área do planalto santareno, que sofrem com os impactos provocados pela expulsão, existe ainda um outro grande impacto, a curto prazo, que é a redução substancial da capacidade de regeneração natural da floresta, já que a remoção das árvores, pela raiz, inclusive

3 SCHLESINGER, Sérgio. O grão que cresceu demais. Rio de Janeiro. FASE, 2006.p 14. 
das Castanheiras, que fazem parte subsistência do homem da Floresta, faz com que se perca o principal meio de regeneração das capoerias, conhecidas como áreas antropizadas ${ }^{4}$.

A monocultura da soja se apresenta como um tipo de cultivo que exige grandes extensóes de terras, por isso o conflito, além do mais há um uso abusivo da mecanização dos campos, que se dá pelo uso de grandes máquinas pesadas, assim, além de não gerar renda direta, os empregos oriundos desta são poucos, o sojicultor prejudica o solo, já que aumenta a compactação deste e contamina os mananciais hídricos com o uso de agrotóxicos 5 .

A ausência de terras tradicionais de uso coletivo para dar continuidade a suas atividades socioculturais e econômicas e a inexistência de contato com seus iguais, faz com que os poucos que ficaram na regiāo futuramente de algum modo também sejam forçados ao êxodo rural, conforme salientado pelos membros da CPT-STM e do Sindicato de Trabalhadores e Trabalhadoras Rurais de Sanatrém - STTR-STM.

Nos dizeres de Fearnside (2006, p. 293), ver-se, portanto, que a promessa de sustentabilidade e proteção ao meio ambiente, que, em tese, seria alcançada com a permuta da pecuária para o cultivo da soja não se consumou.

Os problemas antes detectados tem hoje um fator preponderante, o processo de globalização, que arraigado ao acirramento da competitividade tem provocado em âmbito local o aumento das estratégias de apropriação de terras e de recursos, por parte de empresas nacionais e estrangeiras, com vistas a investimentos imediatos em nichos de mercado, de grande valor global, a exemplo da Cargill e da Amaggi.

Evidencia-se assim, que o Estado tem optado sempre pela solução mais tradicional de desenvolvimento, que é ineficaz social e ambientalmente para a Amazônia, uma vez que tem autorizado, incentivado e construído grandes obras de infraestrutura para garantir a produção de bens primários de exportação, como Belo Monte e agora o Porto de Miritituba, em Itaituba, próximo à Santarém.

O meio ambiente aliado ao desenvolvimento sustentável é um sonho, um álamo que ainda não foi cultivado pela sociedade moderna, e, devido a isso, muitas são as implicaçóes sociais, econômicas, políticas e ambientais que advém de tal dinâmica produtiva, de maneira que se não atentarmos para o mundo que estamos criando, um dia de fato teremos em todo o seu esplendor a sociedade preconizada por Ulrich Beck em sua obra a

4 Para melhor entendimento do assunto recomenda-se a leitura da obra Povos e Comunidades Tradicionais, Movimentos Sociais e Políticas Públicas na Amazônia; ALMEIDA, Alfredo Wagner Berno. Universalização e Localismo, In Amazônia e a Crise da Modernização Org. Maria Ângela e Isolda Maciel da Silveira. ICSA/UFPA: Belém, 2009.

5 JESUS, Cláudio Pereira de. Atributos físicos do solo e produtividade da soja após um ano de integração lavoura-pecuária em área sob plantio direto. 44f. Dissertação (mestrado), Universidade do Estado de Santa Catarina - UDESC Centro De Ciências Agroveterinárias - CAV. Departamento de Solos - DS UFSC, 2006, p. 35. 
La sociedad del riesgo hacia una nueva mordenidad, pois o caminho ali descrito por ele já está sendo trilhado pela humanidade há algum tempo.

Do modo como se apresenta a dinâmica de produção de soja em Santarém, totalmente voltada aos mercados internacionais e amparada pelos ditames do processo econômico global, ver-se claramente que esta pode gerar um número maior de pessoas despossuídas de bens e de direitos fundamentais, sem acesso a liberdades básicas que podem levar ao seu desenvolvimento socioeconômico e cultural e, pior, tudo isso com a aquiescência de nossos governantes, principalmente dos órgãos ligados à regularização de terras ${ }^{7}$.

\section{Justificativa}

\subsection{Cultivo da Soja em Santarém, Violação ao Livre Exercício de Cidadania e Perspectiva de Desenvolvimento Rural sobre a Ótica de Amarya Sen}

No município de Santarém, os membros de comunidades tradicionais, em virtude do agronegócio da soja, quando não se alojam mata à dentro, migram para o centro urbano onde passam a viver em estado deplorável, haja vista que não tem estudos suficientes para se inserir no mercado de trabalho local, sendo obrigados, por isso, a viver à margem da sociedade, quando não mudam para Manaus, Belém e outras cidades, perdendo para sempre o contato com a terra e seu modo de vida. O representante da Comissão Pastoral da Terra em Santarém - CPT-STM, durante a entrevista de campo asseverou bem essa situação ao dizer que:

Com os conflitos surgidos em virtude da posse da terra, muitas comunidades simplesmente desapareceram uma vez que muitos dos moradores

6 BECK, Ulrich. La sociedad del riesgo global. Madrid: Siglo XXI de España Editores S.A., 2002.

7 Para o período entre 1999/2000 e 2006/2007, os impactos em termos de desmatamento, migração e sobre a agricultura familiar estáo bem documentados. A expansão da soja nessa regiáo se deu de maneira acelerada a partir do final da década de 90, inicialmente fomentada pelo governo do estado que elegeu Santarém como área piloto. Os dados de área de cultivo de soja nos municípios de Santarém e Belterra mostram que na safra 1999/2000, a soja ocupava 50 hectares em Santarém e ainda não havia sido registrada para Belterra. Na safra 2003/2004 com o terminal já em operaçáo, a área ocupada com soja em Santarém era de 11 mil hectares e em Belterra de cinco mil hectares. Na última safra, 2008/2009, a área ocupada com soja nesses municípios foi de 30 mil hectares, tendência que comprova as perspectivas iniciais de adequaçấo do planalto santareno à agricultura mecanizada. O histórico de expansão da soja na área de influência da BR-163 é detalhado no diagnóstico do ZEE. Inicialmente estimulada pelo governo do estado e prefeitura de Santarém, o cultivo de soja na regiáo se iniciou de maneira experimental em 1996. Só com o estabelecimento do terminal é que o interesse pelas terras do planalto santareno cresceu. Como resultados imediatos desse projeto destacam-se: (1) ocupaçấo por grandes produtores de áreas devolutas na gleba Pacoval e nos projetos de assentamento do Mojú I e II, (2) compra de áreas de produtores familiares e especulaçáo imobiliária com o valor da terra passando dos $\mathrm{R} \$ 300,00 /$ hectare para até $\mathrm{R} \$ 3000,00 /$ ha nas áreas mais próximas a Mojuí dos Campos e Tabocal; (4) Exxodo rural, com a migração de muitas famílias para a área urbana de Santarém, como a fuga para áreas de terras devolutas ou para regióes mais afastadas do próprio planalto.(Dados do Greenpeace, no artigo Avaliação do Estudo de Impacto Ambiental do Terminal Graneleiro da Cargill em Santarém, 2010, p. 10). 
que tinham lotes ou usam áreas coletivas deixaram de usá-la já que estas passaram a ser de propriedade particular e sua entrada ali não era algo bem quisto, causando ameaças de morte e violência, sem ter onde plantar e manter seu modo de vida, os antigos povos migraram para outras regiốes [...] A extinção das comunidades se dá justamente devido a esta migração, já que não era mais possível manter uma escola com três, quatro alunos, sairia caro para o Estado prestar tal serviço, o mesmo ocorreu com os demais serviços, mesmo os privados, tais como linhas de ônibus (transporte) e comércios, as igrejas se foram, não havia mais fiéis suficientes, assim, gradativamente os vilarejos simplesmente sumiram do mapa, a exemplo das comunidades de Tracuá, Paca e Jenipapo, que ficam no que é hoje o município de Mojuí dos Campos ${ }^{8}$.

Em Santarém, os que insistem em ficar são forçados a tomar banho nos mesmos rios e igarapés nos quais os fazendeiros, os sojicultores, lavam as máquinas usadas para pulverizar pesticidas nas plantaçóes, quando não perdem as áreas comuns em que caçavam, criavam gados ou plantavam ervas e colhiam frutos.

Em Nova Vista, por exemplo, na área de várzea onde vive uma comunidade quilombola, os rios e igarapés estão sendo contaminados pelo agrotóxico usado nas plantaçôes de soja, nessa mesma comunidade, devido a isso, várias crianças foram intoxicadas.

Entre os diferentes agrotóxicos usados na produção de soja no Estado, é necessário destacar o glifosato ${ }^{9}$, ou seu produto formulado mais comum, o Round $U_{p}$, que é o agente mais frequentemente associado ao cultivo de soja, principalmente à geneticamente modificada, e que, nos últimos anos, vem levantando suspeitas na comunidade científica pelo seu potencial de alteração (disrupção) do sistema endócrino humano ${ }^{10}$.

8 Entrevista concedida durante a pesquisa de campo, em setembro de 2012.

9 "O glifosato ( $\mathrm{N}$-(fosfonometil) glicina, $\mathrm{C} 3 \mathrm{H} 8 \mathrm{NO} 5 \mathrm{P})$ é um herbicida sistêmico năo seletivo (mata qualquer tipo de planta) desenvolvido para matar ervas, principalmente perenes. É o ingrediente principal do Roundup, herbicida da Monsanto. Muitas plantas culturais geneticamente modificadas são simplesmente modificaçóes genéticas para resistir ao glifosato. A Monsanto vende sementes dessas plantas com o marca RR (Roundup Ready). O herbicida é absorvido pelas folhas das plantas, não por suas raízes. Segundo a Monsanto, o glifosato liga-se fortemente ao solo, portanto náo vai para os aqüíferos. No solo, é rapidamente metabolizado por desfosforilação. Na Argentina, o uso massivo do glifosato provocou a aparição de resistência, levando a um aumento progressivo das doses usadas, e assim a uma desvitalização e perda de fertilidade do solo. O herbicida elimina também as bactérias indispensáveis à regeneraçấo do solo. No caso da saúde humana, Há indícios de que o glifosato do produto Roundup tenha efeitos nocivos sobre a saúde, como o aumento da incidência de certos tipos de câncer e alteraçóes do feto por via placentária. Estudos in vitro (Walsh et al. 2000) demonstraram que o glifosato reduz a produçáo de progesterona em células de mamíferos, e afeta a mortalidade de células placentárias (Richard et al. 2005). Debate-se se estes estudos permitem classificar o glifosato como disruptor endócrino" (Fonte: Wikipedia).

10 BELO, Mariana Soares da Silva Peixoto; PIGNATI, Wanderlei; DORES, Eliana Freire Gaspar de Carvalho; MOREIRA, Josino Costa; Peres, Frederico. Uso de agrotóxicos na produção de soja do estado do Mato Grosso: um estudo preliminar de riscos ocupacionais e ambientais in Revista Brasileira de Saúde Ocupacional. Vol.37, nº125. São Paulo, janeiro/junho. 2012, p.04. 
O risco de contaminação por produtos tóxicos usados na lavoura não está só nos rios, corre ainda pelas torneiras das pias das escolas que estão funcionando rodeadas por campos de soja em várias comunidades de povos tradicionais, já que estas geralmente são abastecidas com água canalizada de poços artesianos cavados nos arredores da própria escola, ou seja, em meio às plantaçóes.

Tais fatos infelizmente puderam ser comprovados durante nossa pesquisa de campo. Há em Santarém no meio das plantaçóes, em plena atividade, até mesmo escolas e cemitérios, que foram "engolidos" pela soja, como se pode ver pela foto abaixo.

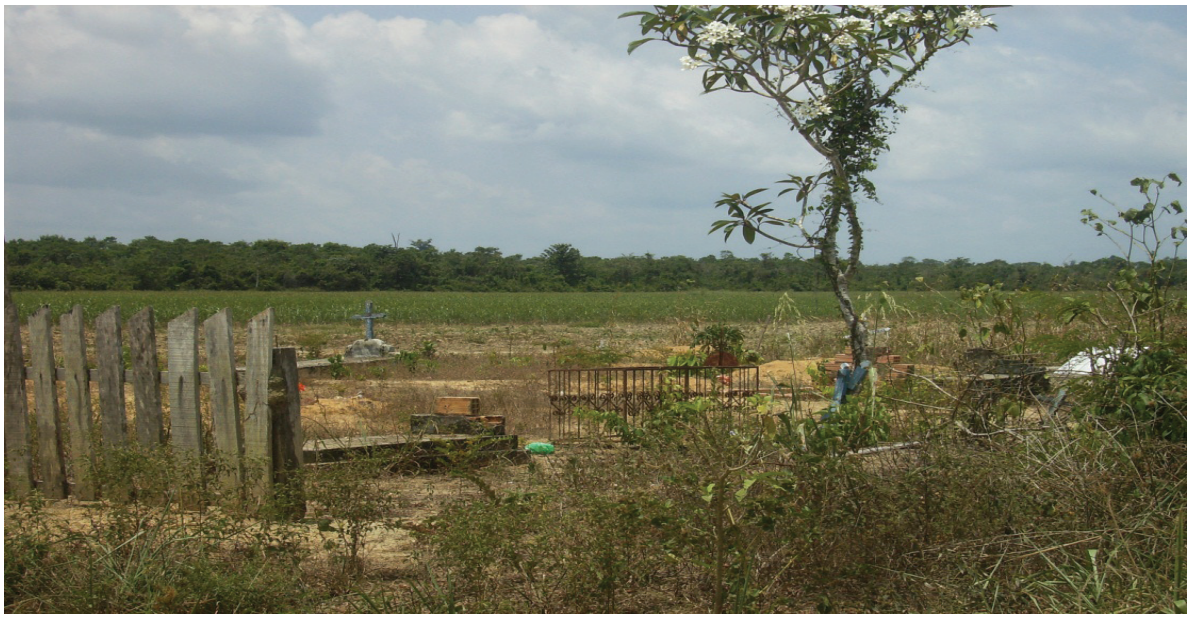

Foto 01: Cemitério tomado pela soja, comunidade de Boa Sorte (Foto de Christiane Aguiar, 2012).

Fonte: Pesquisa de campo, setembro de 2012.

Segundo o membro da CPT-STM é comum vermos situaçóes como esta, descrevendo tais fatos ele assim se manifestou:

As plantaçóes usam a terra em larga escala, abocanhando assim lotes individuais, terras coletivas e até mesmo as próprias agrovilas, invadem áreas de escolas e até mesmo cemitérios [...] Na comunidade Bom Jesus, em Santarém, há até uma escola dentro de uma plantação, ali as crianças bebem água do poço local (contaminada, ao que tudo indica) e ficam sujeitas à pulverização dos agrotóxicos na plantaçáo. Os alunos se quer saem das salas durante a aplicação dos pesticidas, e quando indagados do por que de não saírem, os responsáveis dizem que o produto não fede. Em algumas comunidades, a exemplo do Tracuá, o cemitério foi tragado pelas plantaçóes e há relatos de outras comunidades com o mesmo problema $^{11}$. Grifou-se.

11 Entrevista concedida durante a pesquisa de campo, em setembro de 2012. 
As terras da soja, como dito acima, foram vendidas englobando, às vezes, vilas inteiras, que tinham casas, igrejas, escolas, áreas de recreação, como campos de futebol e cemitérios, algumas dessas vilas não sumiram, mas foram tão abrangidas que simplesmente passaram a fazer parte da própria área da plantação. $\mathrm{O}$ agronegócio veio para mudar de forma permanente a paisagem local. Tais fatos puderam ser constatados em nossa pesquisa de campo, realizada em setembro de 2012.

Em nossa pesquisa, restou claro que este tipo de agronegócio foi implantado na região, sob os auspícios dos governos municipal e estadual, maiores incentivadores daquele, sem levar em conta os reais interesses e potencialidades de desenvolvimento sustentável da população local.

Pelos relatórios da pesquisa, ficou evidenciado que a atividade de exploração econômica em comento veio para alterar quando não, extinguir, de modo irreversível direitos básicos de cidadania, na medida em que retira pessoas de suas, casas, destrói o convívio harmônico do campesinato local em sociedade, impede a propagação e manutenção da identidade cultural, o direito de ir e vir dos cidadãos, o acesso à serviços básicos como saúde, transporte e educação e até mesmo a livre manifestação de cultos, sejam estes católicos ou evangélicos, que são as doutrinas mais comuns naquela zona.

Ademais, é obstáculo para a livre manifestação das liberdades individuais da população rural, que tem restrita suas potencialidades de desenvolvimento socioeconômico, suprimida sua identidade cultural, reduzido o papel de participação cidadã, assim como o contato com a terra, o que dificulta ainda mais as chances de dar continuidade a seus modos de vida, se saber criar, fazer e viver, tal como eram feitos por seus antepassados.

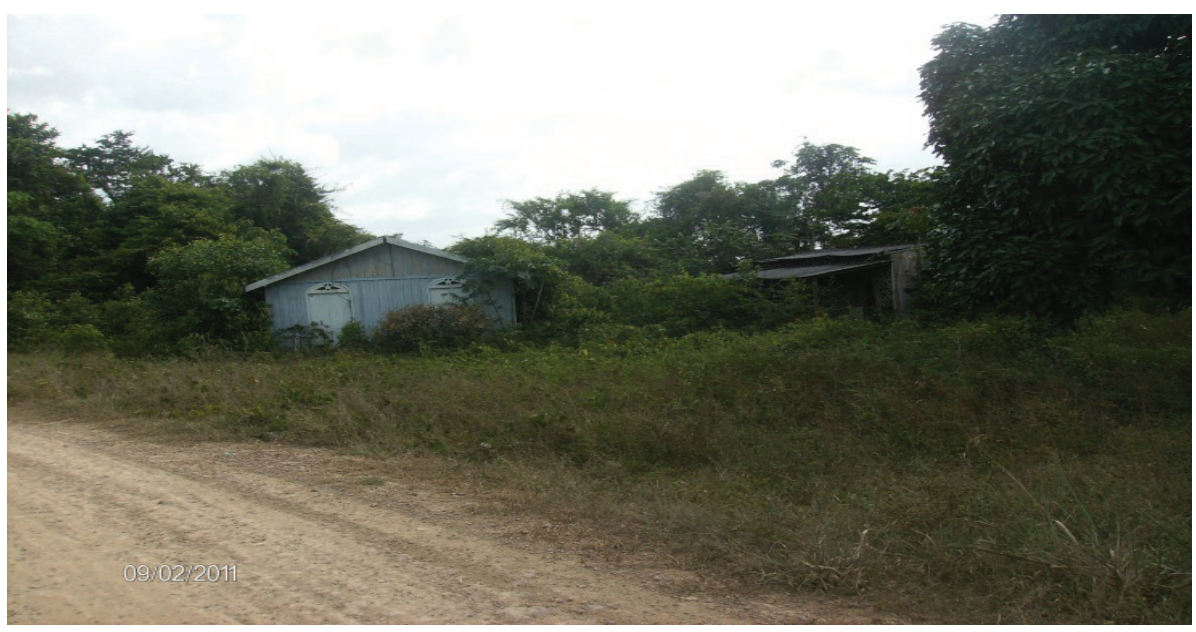

Foto 02: Igreja evangélica abandonada em área de plantio de soja, Ramal da Moça, acesso à comunidade de Igarapé Açú (Foto de Christiane Aguiar, 2011).

Fonte: Pesquisa de campo, setembro de 2012. 


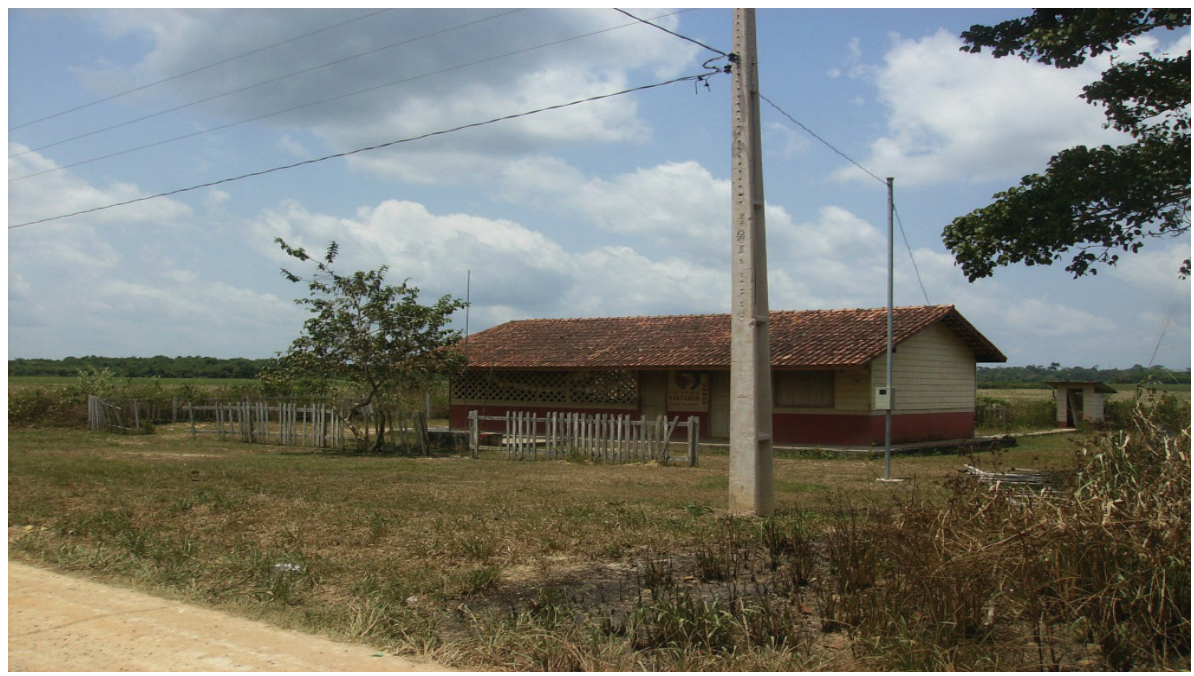

Foto 11: Escola em área de plantio de soja, na comunidade de Boa Sorte (Foto de Christiane Aguiar, 2011). Fonte: Pesquisa de campo, setembro de 2012.

Na comunidade do Ramal da Moça, às proximidades da BR 163, antes viviam 28 famílias, depois que a soja se instalou na região são apenas 9, muitas famílias simplesmente deixaram suas casas, lá até mesmo igrejas são fechadas por falta de fiéis, não há mais serviço de transporte tal como antes, já que os ônibus não tem mais tantos passageiros para transportar, o que vinha duas vezes por semana agora só faz o trajeto até a sede do município uma vez por semana.

Já na comunidade de Boa Sorte, também em Santarém, tanto a escola primária quanto o cemitério da comunidade foram "engolidos" pelos campos de soja. A escola fica no meio da plantação e as crianças não são isentas de assistir às aulas mesmo nos dias de pulverização de pesticidas na lavoura.

De fato a soja afetou várias comunidades tradicionais, tanto de caboclos como as dos quilombolas das áreas das várzeas, estes últimos foram menos afetados, mas ainda assim sofrem as consequências de tal agronegócio, a principal delas é o conflito agrário em virtude da posse da terra ${ }^{12}$.

A CPT-STM informa que muitas comunidades simplesmente sumiram do mapa após o ingresso da soja em Santarém, dentre elas cita algumas: Corta Corda, Tracuá, Paca e Jenipapo, que ficam no que é hoje o município de Mojuí dos Campos. Segundo

12 Estes conflitos foram expostos de forma categórica por André Barreto, que é membro da ONG Terra de Direitos, em Santarém, durante a entrevista realizada em nossa pesquisa de campo. 
a CPT-STM não se sabe com precisão para onde os membros destas comunidades extintas foram, antes se especulava que se deslocavam para o centro urbano (Santarém), mas segundo a CPT-STM é raro encontrar alguém nos bairros que diga que veio de algumas dela, há sim, mas em número ínfimo, não como se pensava (Entrevista de campo, CPT -STM, setembro de 2012).

Segundo a CPT-STM (resposta fornecida em entrevista durante a pesquisa de campo, 2012):

De praxe, os idosos e os jovens vão para os centros urbanos, os primeiros porque iam receber seus benefícios da aposentadoria ou já tinham uma casa nestes e acabaram se alojando por lá, os segundo por causa de estudo ou facilidade de acesso à informação, trabalho, tecnologia, etc., mas o grupo de trabalhadores adultos, no geral, sai das áreas afetadas, compram lotes menores no interior da floresta ou se condensam nos arredores da BR 163, aglutinando-se ao longo dela, à beira da estrada, onde houve um inchaço de algumas comunidades, em virtude dessa dinâmica. Alguns foram para a FLONA Tapajós, onde podem constatar ainda vivos a manutenção de seus modos de criar, fazer e viver, estão bem. Há ainda aqueles que foram para os assentamentos do INCRA, frutos do CR 30, criado em 2005.

Diante disso, se observa que não há um destino certo para os membros dessas comunidades que foram extintas, fato é que essas comunidades estão sofrendo um processo de pulverização e seus membros estão tendo, na maioria dos casos, extintos os modos de vida que eram mantidos por seus antepassados.

Um dos grandes problemas para quem ficou é que com a pouca vegetação que resta nas agrovilas, há, devido ao campo desflorestado, uma constante invasão de insetos e animais peçonhentos (mosquitos, grilos, escorpióes, cobras, etc.), que procuram abrigo nas próprias comunidades, nas árvores que sobraram ao redor das vilas e nas casas, causando assim risco de vida à população local.

Além disso, devido ao uso de agrotóxicos, os animais domésticos criados pelas comunidades, ao ingerirem grãos de soja ou folhas contaminadas morrem ou tem problemas reprodutivos. Ainda não há dados concretos sobre os danos causados pela utilização dos produtos tóxicos, mas eles têm sido perceptíveis, como nos exemplos acima. E é bem provável que no futuro a própria população também venha a sofrer com problemas de saúde, no geral, respiratórios e cancerígenos (CPT-STM, 2012).

Ainda segundo a CPT-STM (2012), mesmo diante de tudo isso, algumas comunidades, no caso, as que acabaram ficando, não veem o sojeiro como um malfeitor, pelo contrário, o veem como o "cumpadre, o que dá carona quando estấo a pé nos ramais feitos por eles, que leva o filhos dos membros destas doentes para os hospitais da grande cidade, que ajuda na reforma da igreja, que ajuda o time de futebol local, etc.”. 
Dentro desse contexto, observa-se que isso só ocorre porque na verdade o sojicultor acabou assumindo a figura do Estado, dando às comunidades o que sempre foi obrigação deste e não daquele, o Estado não faz nenhum tipo de política pública que realmente leve em conta os direitos, interesses e necessidades dessas populaçóes, assim, ver-se que houve a criação de uma relação de dependência entre as comunidades e os produtores de soja em Santarém.

Outro fruto danoso da soja em Santarém é a contaminação de rios e igarapés, que estão poluídos, neste caso, três comunidades indígenas em fase de reconhecimento estão sendo afetadas, são elas, a do Açaizal, Ipaupixuna, e Cavada, todas situadas no planalto, próximo a PA 370 (CPT-STM 2012).

O povo de Açaizal se sente intimidado pela presença das plantaçóes, pois os membros deste ou mesmo seus animais não podem se quer passar pelo local do cultivo. Além disso, reclamam do assoreamento e da contaminação por agrotóxicos dos igarapés onde a comunidade pesca. Por essa razão, os moradores de Açaizal lutam, desde 2004, para que o governo federal reconheça a comunidade como uma terra indígena e retire os sojeiros da área, Açaizal, é uma das comunidades de povos ressurgidos que está situada na Gleba Nova Olinda, palco de muitos conflitos em virtude da posse e acesso à terra.

No que tange às comunidades quilombolas, André Barreto da ONG Terra de Direitos ressaltou durante a entrevista que a comunidade de Nova Vista, na localidade de Ituqui, na área de várzea, vem sofrendo constantemente em virtude da chegada da soja em tal território, segundo ele, os donos das plantaçóes impedem que a comunidade utilize as terras coletivas, que eram usadas para a pastagem do gado e impendem a entrada destes naquelas, o que tem gerado fortes conflitos entre ambos os lados, inclusive com caso de registro de lesóes corporais cometidos pelos empregados dos sojeiros contra membros da comunidade, além disso, há relatos de contaminação das águas dos rios e igarapés que abastecem a região por agrotóxicos ${ }^{13}$.

Baseado na análise de todos esses dados coletados em referências bibliografias e em nossa pesquisa de campo, escolhemos como obra primordial para análise do tema, a obra de Amartya Sen, Desenvolvimento como liberdade, que traz a ideia de crescimento econômico como liberdade, em todos os sentidos.

Neste caso em apreço, a obra de Sen se encontra em total consonância com o tema em questão, na medida em que ele assevera que considerar estes dois cenários acima como distintos é um erro fatal da economia atual, ou seja, náo se pode desassociar a atual conjuntura econômica do contexto democrático político e social vigente ${ }^{14}$.

13 Entrevista concedida durante pesquisa de campo, em setembro de 2012.

14 SEN. Amartya. Desenvolvimento como liberdade. São Paulo. Companhia das Letras, 2000, pp. 177-178. 
No Brasil, o PIB ainda é tido como algo de suma importância, principalmente com o prognóstico de crescimento econômico atual. Hoje o país é sexta economia do mundo, tendo ultrapassado a Grã Bretanha, todavia, a realidade socioeconômica brasileira está distante de se equiparar à inglesa ${ }^{15}$.

O PIB não reflete a qualidade de vida das pessoas. É esse o pensamento de Sen e que permeia toda nossa discussão em torno da temática da soja em Santarém.

Ora a questão do PIB brasileiro se pauta nessa acepção, pois assim como o "desenvolvimento" da região Amazônica, do município de Santarém, com a chegada dos grandes sojicultores, trouxe avanços na renda destes e aumentou o PIB do município, ao mesmo tempo esse desenvolvimento não se revelou nada próspero para a populaçáo local, pelo contrário, acabou por fomentar ainda mais a concentração de renda e a dizimar por completo direitos fundamentais da populaçáo local ${ }^{16}$.

Para Sen, essas distorçóes apontam para um novo modelo de desenvolvimento, baseado na expansão das melhorias das condiçóes de vida das pessoas ${ }^{17}$.

Assim, desenvolvimento pode ser visto, como um processo de expansão das liberdades reais de que desfrutam as pessoas. Enforcar a liberdade humana contrasta com concepçóes mais estreitas do desenvolvimento, como as que o identificam com o crescimento do produto nacional bruto ou com o aumento da renda pessoal, ou com a industrialização, ou com o avanço tecnológico, ou com a modernização social, que na maioria das vezes fomentam o desrespeito à garantia dos modos de vidas de populaçóes que estão distantes dos modelos socioeconômicos impostos pelo Estado.

Nesse aspecto, cumpre ressaltar que o desenvolvimento não é jamais remetido a desigualdades, seja no interior de naçôes ou países ou entre eles. É meramente uma questão

15 O PIB brasileiro cresceu 2,7\% em 2011 e alcançou R \$ 4,143 trilhóes, segundo dados divulgados pelo Instituto Brasileiro de Geografia e Estatística (IBGE) no dia 06.03.2012, do site do Instituto.

16 Devido ao fato de que a soja requer investimentos pesados de capital em maquinaria, preparação do terreno e insumos agrícolas, essa cultura é inerentemente de domínio de empresários ricos da agroindústria, e náo de agricultores pobres. Uma extrema concentraçáo de renda tem sido associada com a soja onde quer que essa cultura esteja na América Latina. A concentração de renda e a influência política associada de elites poderosas têm repercussōes negativas em todas as sociedades onde estas transformaçôes estão acontecendo, Fearnsid, 2006, p. 294.

17 "A utilidade da riqueza está nas coisas que ela nos permite fazer — as liberdades substantivas que ela nos ajuda a obter. mas essa relação não é exclusiva (porque existem outras influências significativas em nossa vida, além da riqueza) nem uniforme (pois o impacto da riqueza em nossa vida varia conforme outras influências). É tão importante reconhecer o papel crucial da riqueza na determinação de nossas condiçóes e qualidade de vida quanto entender a natureza restrita e dependente dessa relaçăo. Uma concepção adequada de desenvolvimento deve ir muito além da acumulaçấo de riqueza e do crescimento do Produto nacional bruto e de outras variáveis relacionadas à renda. sem desconsiderar a importância do crescimento econômico, precisamos enxergar muito além dele”, relato de Amartya Sen, na obra Desenvolvimento como liberdade, p. 28. 
de preocupação com o indivíduo, de gerar qualidade de vida a este, seja ele membro de uma grande cidade ou de uma agrovila no meio da floresta amazônica.

A liberdade, segundo Sen, é duplamente "central para o desenvolvimento", pela "razão avaliatória", uma preocupação substantiva mediante a qual a estimativa do progresso deve dar conta da ampliação efetiva, levando em conta que "a avaliação do progresso tem de ser feita verificando-se primordialmente se houve aumento na liberdade das pessoas", bem como em virtude da razão da eficácia, uma vez que "a realização do desenvolvimento depende inteiramente da livre condição das pessoas" 18 .

Ora, no caso em destaque, o alargamento da fronteira agrícola em Santarém não levou em conta a realidade local, as necessidades da população, pelo contrário, lhe foi imposto, agraciado por políticas públicas que beneficiavam os grandes produtores em detrimentos das populaçóes tradicionais ali existentes ${ }^{19}$.

Para assegurar o desenvolvimento econômico atrelado às liberdades, aos direitos fundamentais, Amartya Sen destaca que a perspectiva das capacidades, que nesse seria caso de crescimento econômico, por meio da implantação da soja, somente tem validade se todos forem incluidos no debate público; todos nestes caso, seria inclusive os membros dos povos tradicionais atingidos pelo cultivo da soja; recaindo então sua teoria no conceito de democracia participativa, levantado por Boaventura de Sousa Santos ${ }^{20}$, que ressalta que só com a adoção de pelo menos cinco liberdades instrumentais esta pode ser feita, quais sejam: 1) Liberdades políticas: Incluem os direitos civis, e referem-se à liberdade de escolha por parte das pessoas sobre quem deve governar e porque, além dos direitos de fiscalização e crítica dos governantes através de uma imprensa livre e atuante; 2) Facilidades econômicas: Oportunidades por parte das pessoas para utilizar recursos econômicos para o consumo, produção ou troca. Para isto, os mecanismos de mercado podem ter um valor fundamental, já que permitem a livre circulação de pessoas e produtos na economia; 3) Oportunidades sociais: Referem-se aos serviços de saúde, educação, etc., que permitem ao indivíduo não apenas viver melhor em sua vida privada (escapando da miséria através de um trabalho mais bem qualificado, por exemplo), quanto também participar melhor da vida pública (a capacidade de ler jornais é fundamental para a atividade política, por

18 SEN. Op. cit., p. 18.

19 Segundo Sérgio Schlesinger (2008, p. 20), a expansão geográfica da soja é mais intensa nas regiōes Norte e Nordeste do Brasil, o referido pesquisador, alegou no Seminário "A Expansáo da Soja no Baixo Amazonas”, em 2 a 4 de dezembro de 2005, que as promessas iniciais de emprego não passam de falácias, o que se observa, ao contrário, é uma redução do emprego no setor da soja (campo) e aumento de concentração fundiária. Ao comparar a agricultura familiar com a patronal deduz que a agricultura familiar gera muito mais emprego se estimarmos uma área de 100 ha do que a destinação de área do mesmo tamanho para o plantio de soja.

20 SANTOS, Boaventura de Sousa, A Gramática do tempo, para uma nova cultura política. Cortez Editora. 3a Edição, São Paulo, 2010, p. 372. 
exemplo); 4) Garantias de transparência: Referem-se à necessidade de uma pessoa esperar sinceridade em sua relação com outras pessoas, instituiçôes e com o próprio Estado. Além de essencial para a coesão social, ela pode ter papel importante na prevenção da corrupção, por exemplo, e, por fim 5) Segurança protetora: Resguarda os vulneráveis de caírem na miséria extrema através de uma rede de seguridade social e outras medidas que visem às garantias mínimas de sobrevivência das pessoas ${ }^{21}$.

Embora o Brasil tenha evoluído economicamente nos últimos anos ele ainda tem um longo caminho a percorrer para que alcance estas liberdades em sua plenitude.

Essas liberdades propostas por Sen e repensadas por Boaventura não só permitem ao indivíduo aumentar a sua capacidade (reforçando sua condição de agente) como reforçam também umas às outras. O reforço da condição de agente do indivíduo permite-nos também considerar as liberdades instrumentais como importantes por si só.

Fora isto, há evidências claras de que a adoção destas liberdades é um fator a favor, e não contra, o crescimento econômico, mas de forma alguma elas foram implantadas e garantidas em nenhum momento da história de ocupação do território amazônico.

Podemos dizer assim, que uma sociedade mais bem educada pode aspirar receber empregos mais sofisticados; a transparência gera confiança nos investidores, que investem mais, etc. Isto quer dizer que o argumento formulado no início que opunha direitos e crescimento econômico estava totalmente mal formulado, na medida em que não se conquista as liberdades depois, mas sim, antes da opulência.

Essas ideias preconizadas por Sen de fato se intercalam com a realidade de Santarém uma vez que o Estado não planejou e organizou a entrada da nova commodities na região, mas somente a incentivou sem fazer nenhuma orientação, investimento em pesquisa ou estudo de impacto socioeconômico e ambiental.

As teorias de Sen, se aplicadas pelo Estado e pelos empreendedores capitalistas bem se adequariam à realidade da Amazônia, mas não vislumbramos a priori nenhuma prática dessas na região ${ }^{22}$.

21 SANTOS. Op. cit., pp. 54-57.

22 Não é de hoje a Amazônia é saqueada, desmatamento, biogrilagem, exploração madeireira ilegal, cultivo da soja e pecuária extensiva representam alguns dos grandes problemas que assolam a Amazônia. Desde a chegada dos europeus, responsáveis pela dizimação de culturas, povos e riquezas naturais - passando pela explosão populacional durante o ciclo da borracha, período no qual milhares de nordestinos migraram para a região em busca do "ouro negro" até a atual fase "desenvolvimentista", que promove a devastação da floresta para a criação de gado e plantações de soja - a ação predatória do homem demonstra o descaso em relação ao meio ambiente, às fragilidades dos sistemas de monitoramento e à ineficiência das políticas públicas na Amazônia.Para melhor entendimento do assunto recomendo a leitura da obra Meio ambiente e mudanças climáticas na Amazônia, reportagens dos participantes do Laboratório Ambiental para Estudantes de jornalismo, p. 13. 
Nesse sentido, Sen observa diretamente que a capacidade é um tipo de liberdade. Um ponto nevrálgico de um novo exame da desigualdade é justamente a análise difusa da relação conceitual da capacidade com as muitas classes de liberdades tradicionalmente estudadas (positivas ou negativas, substantivas ou formais) e do modo como a capacidade é a medida mais adequada para determinar aumentos ou diminuiçóes de liberdade em variados contextos interdependentes de avaliação (pobreza, desníveis de renda, padróes de vida, justiça, desigualdade entre os sexos, desigualdade de oportunidades, etc.). Nesse caso, a capacidade de liberdade de desenvolvimento dos povos tradicionais estaria totalmente violada uma vez que foi suprimida pela atuação dos sojicultores e do Estado.

$\mathrm{O}$ que seria então uma sociedade humanamente desenvolvida levando em conta essas capacidades? Segundo o igualitarismo de Sen, seria uma sociedade em que todos tenham igual liberdade para escolher seus objetivos e finalidades particulares (as coisas que valorizam por alguma razão) e nessa busca enfrentem o mínimo possivel de obstáculos à realização de suas potencialidades.

Ora, nesse caso, levando-se em conta tal preceito, a inserção de novas fronteiras agrícolas priva a liberdade de muitos; o direito de ir e vir torna-se violado, a terra em que muitas geraçóes labutavam deixa de existir, para dá vazão a empreendimentos agrícolas que demandam grandes extensóes de áreas e abusam do uso da tecnologia, deixando de lado a máo de obra local e por vezes dizimam por completo alguns modos de vida, quando não, submetem a risco de morte, como no caso das escolas situadas em meio às plantaçóes, onde crianças assistem aulas até mesmo no dia da pulverização de agrotóxicos, ou seja, os obstáculos a realizaçóes das potencialidades desses povos são muitos, o que fatalmente pode levá-los a não se desenvolver adequadamente, já que sua capacidade de desenvolvimento foi limitada ${ }^{23}$.

Em síntese, atrelando o presente estudo a Sen, podemos dizer que a "abordagem da capacidade" de se auto gerenciar, de ter liberdade para decidir é superior às outras principalmente por ser informacionalmente mais rica, as capacidades devem ser respeitadas para se atingir o bem comum e o desenvolvimento econômico deve respeitar cada uma delas, de modo a possibilitar acesso a meios de vida qualitativos a todos, sejam eles, os donos dos agronegócios ou simplesmente um caboclo ou um membro de uma comunidade quilombola santarena.

23 No sul do país, entre 1970 e 1973, a expansão do cultivo de soja se deu, em sua quase totalidade, sobre terras até então destinadas ao cultivo de arroz, feijão, mandioca, milho e café. A valorização das terras inaugurou um movimento de expulsão de pequenos agricultores que dura até hoje. Nos anos 1970, mais de 2,5 milhóes de pessoas abandonaram o campo no Paraná e 109.000 pequenos estabelecimentos deram lugar à soja. No mesmo período, o Rio Grande do Sul perdeu 300.000 propriedades rurais (Fearnside, 2001). 


\section{Objetivos}

Demonstrar que a dinâmica do cultivo de soja em Santarém mantém relação direta com as causas de aumento de violaçôes de direitos fundamentais das populaçôes locais da região, sobretudo, no que tange a direitos básicos de cidadania e na toma de decisóes em prol de um desenvolvimento rural sustentável para essa parte do território amazônico.

Identificar, em conjunto com a doutrina de desenvolvimento de Amartya Sen, os conflitos socioambientais e violaçóes de direito que sejam frutos do emprego da monocultura da soja, com destaque à estrutura fundiária anteriormente existente, de modo a demonstrar que o modelo empregado pelo sojicultor é prejudicial à sadia qualidade de vida e ao desenvolvimento das liberdades individuais dos membros das comunidades locais.

Analisar o processo de inserção da nova fronteira agrícola da soja no município de Santarém e suas interfaces com as comunidades locais ali existentes, sobretudo, quanto à propagação de atos que desencadearam violaçóes de direitos fundamentais e impedem o desenvolvimento de liberdades e direitos individuais que poderiam levar os cidadãos ali residentes a terem o pleno gozo de seu modo de fazer, criar e viver e, assim, poder desarrolhar livremente suas potencialidades socioeconômicas e exercer sua identidade cultural de maneira a preservar seus modos de vida às futuras geraçóes.

\section{Conclusões}

No presente trabalho, procurou-se adentrar na dinâmica de exploração do agronegócio da soja no município de Santarém, no Pará, onde por meio de estudos bibliográficos, pesquisa de campo, pesquisas na internet e visitas às propriedades de soja e comunidades locais, pôde-se detectar que a soja foi trazida para a região com o intuito de desenvolvê-la, mas acabou gerando fortes impactos sociais e ambientais na área de sua abrangência.

A Amazônia sempre foi um criadouro de oportunidades para o agronegócio, nela há fartura de terras férteis e de recursos naturais com grande valor no mercado econômico global, porém, o ingresso desses novos atores sociais sempre traz riqueza para uns e pobreza para outros, na medida em que a inserção deles nunca é acompanhada de estudos que possam atestar além da viabilidade do exercício da nova atividade econômica, o prejuízo às comunidades locais, seja pela exclusão ou pela inserção dessas nos empreendimentos.

Em Santarém, os povos indígenas, na Gleba Nova Olinda, os quilombolas, das regióes de várzeas, e, em sua maior parte, os caboclos que vivem em agrovilas nos ramais ao longo da BR 163 e na região do planalto são os mais afetados.

E, dentro desse contexto tem se sobressaído preocupaçôes elementares, como o direito fundamental de acesso à terra por parte dos povos tradicionais, a garantia de direitos individuais aos cidadãos do campo, o acesso a meios de desenvolvimento social, econômico 
e cultural que garantam a preservação e existência dos antigos e necessários modos de vida dos moradores da Amazônia.

Partimos da premissa de que para solucionar tais conflitos e preservar esses modos de vida, faz-se necessária a presença do Estado como de fato o deve ser, como um ente protetor, garantidor dos direitos básicos da população, principalmente das minorias, no caso, dos povos tradicionais diretamente afetados; sendo também necessária uma real aplicação dos princípios da participação cidadã e de democracia participativa, que possibilitem à Administração atuar de forma a prevenir e evitar violaçóes de direitos fundamentais e outros impactos socioambientais em Santarém; deve ser evitado o ingresso de novos produtores na região; faz-se necessário, de imediato, mapear e avaliar corretamente todos impactos socioculturais desencadeados pelo cultivo da soja em Santarém; é crucial que a atuação do Estado para ocupação e exploração econômica da Amazônia leve em conta os modos de vida, de criar, fazer e viver dos povos que nela residem, pois em náo o fazendo, fatalmente estará levando estes à extinção.

\section{Referências}

A Expansão do monocultivo de soja em Santarém e Belterra: injustiça ambiental e ameaça à segurança alimentar. Vânia de Carvalho e Letícia Tura (FASE-Amazônia). "Projeto Soja, Sociedade e Meio Ambiente, FASE Amazônia”. Visualizado em março de 2012 http://www.comova.org.br/pdf/A-Expansao-do-monocultivo-de-soja-emSantarem-e-Belterra.pdf

BELO, Mariana Soares da Silva Peixoto; PIGNATI, Wanderlei; DORES, Eliana Freire Gaspar de Carvalho; MOREIRA, Josino Costa; Peres, Frederico. Uso de agrotóxicos na produção de soja do estado do Mato Grosso: um estudo preliminar de riscos ocupacionais e ambientais in Revista Brasileira de Saúde Ocupacional. Vol.37, nº125. São Paulo, janeiro/junho, 2012.

BECK, Ulrich. La sociedad del riesgo global. Madrid: Siglo XXI de España Editores S.A., 2002.

CARVAlHO, Renata. "Amazônia rumo ao 'ciclo da soja”. Amazônia Papers, 2, Ano I. Amigos da Terra, Programa Amazônia, 1999.

CASTRO, Edna, in Amazônia: região universal e teatro do mundo/organização Willi Bolle, Edna Castro, Marcel Vejmelka. São Paulo. Globo, 2010.

Entrevista concedida durante a pesquisa de campo, em setembro de 2012.

FEARNSIDE, P.M. 2006. O cultivo da soja como ameaça para o meio ambiente na Amazônia brasileira.pp. 281-324 In: L.C. Forline, R.S.S. Murrieta and I.C.G. Vieira (eds.) Amazônia além dos 500 Anos. Museu Paraense Emílio Goeldi, Belém, Pará, Brasil. 
FEARNSIDE, P.M. O cultivo da soja como ameaça para o meio ambiente na Amazônia Brasileira. Belém. Museu Emílio Goeldi, 2006.

JESUS, Cláudio Pereira de. Atributos físicos do solo e produtividade da soja após um ano de integração lavoura-pecuária em área sob plantio direto. 44f. Dissertação (mestrado), Universidade do Estado de Santa Catarina - UDESC Centro De Ciências Agroveterinárias - CAV. Departamento de Solos - DS UFSC, 2006.

KOHLHEPP, G. Desafios do desenvolvimento regional entre sustentabilidade e mega -programas econômicos: o caso da Amazônia brasileira. Revista de Estudos Avançados. São Paulo. USP, 2000.

LOUREIRO, Violeta Refkalesfsky. Amazônia: estado, homem, natureza. 2a Edição, Belém. Cejup. 2004.

OLIVEIRA, Janete Marília Gentil Coimbra de. Expansão urbana e periferização de Santarém-PA, Brasil: questóes para o planejamento urbano. Diez años de cambios en el Mundo, en la Geografía y en las Ciencias Sociales, 1999-2008. Actas del X Coloquio Internacional de Geocritica, Universidad de Barcelona, 26-30 de mayo de 2008, com acesso em http://www.ub.es/geocrit/-xcol/268.htm, visita feita no dia 23.05.2012.

Os impactos da safra da soja nos anos de 2008 e 2010, Repórter Brasil: em http://www. reporterbrasil.com.br/estudo_soja_cma_reporter_brasil_2010.pdf, acesso no dia 30.04.2012.

Povos e Comunidades Tradicionais, Movimentos Sociais e Políticas Públicas na Amazônia; ALMEIDA, Alfredo Wagner Berno. Universalização e Localismo, In Amazônia e a Crise da Modernização Org. Maria Ângela e Isolda Maciel da Silveira. ICSA/ UFPA: Belém, 2009.

SANTILLI, Juliana, Socioambientalismo e novos direitos. São Paulo: Petrópolis, IEB, 2005, p. 185-243.

SANTOS, Boaventura de Sousa, A gramática do tempo, para uma nova cultura política,

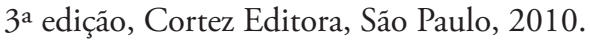

SCHLESINGER, S. O grão que cresceu demais. Rio de Janeiro. FASE, 2006.

SHIRAISHI NETO, Joaquim. Direito dos povos e das comunidades tradicionais no Brasil: declaraçóes, convenções internacionais e dispositivos jurídicos definidores de uma política nacional. Joaquim Shiraishi Neto, org. Manaus: UEA, 2007.

SEN, Amartya Kumar, Desenvolvimento como Liberdade, Companhia das Letras, São Paulo, 2007. 